University of Nebraska - Lincoln

DigitalCommons@University of Nebraska - Lincoln

Biological Systems Engineering: Papers and

Publications

Biological Systems Engineering

2012

\title{
A 3-D Computational Fluid Dynamics Model for Forced Air Cooling of Eggs Placed in Trays
}

\author{
Vikas Kumar \\ University of Nebraska-Lincoln \\ Ai Pheeng Wee \\ University of Nebraska-Lincoln \\ Sohan Birla \\ University of Nebraska-Lincoln, sbirla2@unl.edu \\ Jeyamkondan Subbiah \\ University of Nebraska-Lincoln, jeyam.subbiah@unl.edu \\ Harshanardhan Thippareddi \\ University of Nebraska-Lincoln, harsha15@uga.edu
}

Follow this and additional works at: https://digitalcommons.unl.edu/biosysengfacpub

Part of the Biological Engineering Commons

Kumar, Vikas; Wee, Ai Pheeng; Birla, Sohan; Subbiah, Jeyamkondan; and Thippareddi, Harshanardhan, "A 3-D Computational Fluid Dynamics Model for Forced Air Cooling of Eggs Placed in Trays" (2012).

Biological Systems Engineering: Papers and Publications. 208.

https://digitalcommons.unl.edu/biosysengfacpub/208

This Article is brought to you for free and open access by the Biological Systems Engineering at DigitalCommons@University of Nebraska - Lincoln. It has been accepted for inclusion in Biological Systems Engineering: Papers and Publications by an authorized administrator of DigitalCommons@University of Nebraska Lincoln. 


\title{
A 3-D Computational Fluid Dynamics Model for Forced Air Cooling of Eggs Placed in Trays
}

\author{
Vikas Kumar, ${ }^{1}$ Ai Pheeng Wee, ${ }^{1}$ Sohan Birla, ${ }^{1}$ Jeyamkondan Subbiah,,${ }^{1,2}$ and Harshavardhan Thippareddi ${ }^{2}$ \\ 1. Biological Systems Engineering, University of Nebraska-Lincoln \\ 2. Food Science and Technology, University of Nebraska-Lincoln \\ Corresponding author — Dr. Jeyamkondan Subbiah, 212 L.W. Chase Hall, University of Nebraska, \\ Lincoln, NE 68583-0726, 402-472-4944, jsubbiah2@unl.edu
}

\begin{abstract}
Shell eggs must be cooled quickly after laying for controlling Salmonella Enteritidis (SE) growth. To fulfill a research need identified by Food Safety and Inspection Service (FSIS), a 3-D Computational Fluid Dynamics (CFD) model was developed to predict the temperature of eggs placed on a tray ( 6 rows $\times 5$ columns $)$ under forced air cooling. The continuity, momentum, and energy equations were solved along with standard k- $\varepsilon$ turbulence model using PHOENICS software. The model was validated by conducting experiments in a wind tunnel at various air temperatures $\left(7-11^{\circ} \mathrm{C}\right)$ and velocities $(0.3-$ $0.7 \mathrm{~m} / \mathrm{s}$ ). Root mean square error for predicting yolk temperatures was within $1{ }^{\circ} \mathrm{C}$. Finally, the CFD model was integrated with a microbial growth model to estimate the risk of SE growth during cooling. This model can be incorporated into the FSIS risk assessment model for more accurate estimation of SE risk in shell eggs.
\end{abstract}

Keywords: computational fluid dynamics (CFD), egg tray, simulation, microbial growth, validation, food safety

\section{Introduction}

According to a Centers for Disease Control and Prevention (CDC) report, 1.4 million Salmonella infections occur each year in the United States, with majority (ca. 94\%) of the cases to be foodborne (CDC, 2006). Eggs have been identified as the major vehicle for Salmonella accounting for $36.5 \%$ of the outbreaks (CDC, 2007). From 1976 to 1995, SE infections in egg containing foods increased eight folds. The recent outbreak of Salmonella Enteritidis (SE) infections associated with shell eggs caused a nationwide voluntary recall of shell eggs (CDC, 2010).

Salmonella contamination of the eggs can occur through either vertical or horizontal transmission. While the horizontal transmission can occur with a variety of Salmonella serotypes, vertical transmission is exclusively related to Salmonella Enteritidis (SE). The SE infection of the reproductive tract can occur, resulting in contamination of the egg components before oviposition known as vertical transmission. While SE contamination can occur in any component of the egg, the potential risk of SE growth is greater in the yolk as the organism can grow faster due to higher $\mathrm{pH}$ and the nutrient composition of the yolk. Proper cooling of the eggs subsequent to lay is critical in minimizing potential growth of SE in the egg. The cooling rate depends on the initial egg temperature, cooling air temperature, air flow/velocity, thermal properties of the tray/packaging material and the location of the egg within the tray. Feddes et al. (1993) reported that air circulation is essential for effective cooling of eggs within an enclosed box. Thus, it is necessary to determine and specify the proper cooling rate required to minimize the potential growth of SE rather than the current FDA specification of storing the eggs in a cooler set to $7.2^{\circ} \mathrm{C}$. Accurate heat transfer models coupled to microbial (SE) predictive models can provide the necessary information to specify the safe cooling rate for the eggs to mitigate the risk of SE infections from shell eggs.

The Food Safety and Inspection Service (FSIS) of the United States Department Agriculture (USDA) developed a risk assessment model for SE in eggs and egg products.

This risk assessment model was based on simplistic exponential cooling rate for cooling of eggs. The USDA-FSIS identified the need to develop a tool to predict internal temperature of shell eggs during cooling in order to predict potential growth of SE during cooling and subsequent storage (FSIS, 2005).

Numerical methods such as finite difference, finite element and finite volume have been used to model heat transfer in various meat products. Sabliov et al. (2002) developed a 2-D axisymmetric finite element heat transfer model to predict the center temperature of a shell egg during cryogenic cooling. Almonacid et al. (2007) developed a 2-D heat transfer model for shell eggs using finite difference and finite element methods and integrated it with microbial growth model of SE. Gumudavelli et al. (2007a) developed a 2-D axisymmetric finite element model for cooling of an egg under forced con- 


$\begin{array}{ll}\text { Nomenclature } \\ C_{\mathrm{p}} & \text { specific heat capacity }(\mathrm{J} /(\mathrm{kg}-\mathrm{K})) \\ \mathrm{k} & \text { thermal conductivity }(\mathrm{W} /(\mathrm{m}-\mathrm{K})) \\ k & \text { turbulent kinetic energy }\left(\mathrm{m}^{2} / \mathrm{s}^{2}\right) \\ p & \text { pressure }(\mathrm{Pa}) \\ q_{o} & \text { initial physiological state of cells } \\ \mathrm{RMSE} & \text { root mean square error } \\ S & \text { source terms } \\ T & \text { temperature }\left({ }^{\circ} \mathrm{C}\right) \\ T^{\prime} & \text { fluctuating temperature component } \\ t & \text { time }(\mathrm{s}) \\ T_{\mathrm{a}} & \text { inlet air temperature }\left({ }^{\circ} \mathrm{C}\right) \\ T_{\mathrm{s}} & \text { surface temperature }\left({ }^{\circ} \mathrm{C}\right) \\ u & \text { velocity }(\mathrm{m} / \mathrm{s}) \\ \mathbf{u}_{\mathrm{f}} & \text { frictional velocity, } \mathrm{m} / \mathrm{s} \\ u^{\prime} & \text { fluctuating velocity component }\end{array}$

$y \quad$ cell concentration in $\log \mathrm{CFU} / \mathrm{g}$

$\mathrm{Y}^{+} \quad$ dimensionless wall distance $\left(\mathrm{u}_{\mathrm{f}} \times\right.$ normal wall distance $\left./ v\right)$

$\mu \quad$ dynamic viscosity (Pa-s)

$\mu_{\max } \quad$ maximum specific growth rate in terms of $\log _{\mathrm{e}} \mathrm{CFU} / \mathrm{g}$ in $1 / \mathrm{h}$.

$\rho$ density of air $\left(\mathrm{kg} / \mathrm{m}^{3}\right)$

$\varepsilon \quad$ turbulent energy dissipation rate $\left(\mathrm{m}^{2} / \mathrm{s}^{3}\right)$

$\sigma_{k} \quad$ turbulent Prandtl number for kinetic energy

$\sigma_{\varepsilon} \quad$ turbulent Prandtl number for energy dissipation rate

$\Delta \mathrm{T}$ temperature difference between egg and cooling/heating air

$\mathrm{K}_{\text {distw }} \quad$ von Karman's constant $\times$ normal wall distance, where von

Karman's constant is 0.41

$v \quad$ kinematic viscosity, $\mathrm{m}^{2} / \mathrm{s}$

Subscript

lam laminar vection. Their simplified model solved heat conduction equation by assigning uniform overall heat transfer coefficient at the external surface of the egg. Kumar et al. (2009) developed a 3-D CFD model to predict the temperature distribution within an egg subjected to forced air cooling. They assumed conductive heat transfer within the egg and convective heat transfer in the air.

None of these previous models represents the actual scenarios encountered in industrial cooling operations. Generally eggs are placed on trays, and trays are stacked on each other on a pallet. The fluid flow pattern and the heat transfer characteristics of each egg placed on a tray would be different due to its varying location from the external environment. Considering the fact that temperature distributions are non-uniform in all eggs, there is a need to develop a CFD model for predicting temperatures of multiple eggs placed on an egg tray. The objectives of this research were to:

1. develop a 3-D CFD model to predict the temperature of multiple eggs placed on an egg tray and validate the model in wind tunnel under various conditions,

2. extend the 3-D heat transfer models for multiple trays and validate the extended model in wind tunnel,

3. integrate the CFD model with a microbial model to predict potential growth of SE.

\section{Materials and Methods}

\subsection{Simulation and experimentation with single trays (Obj. 1)}

\subsubsection{Physical model}

In shell egg industry, eggs are placed on plastic trays (six rows and five columns) and cooled under forced convection condition. These trays are stacked one over the other from the floor to the ceiling. Fans are normally mounted on the ceiling on one side of the room to circulate the air (Fig. 1A). To simplify the model, we assumed that there was no variation of air velocity and temperature along the height or width of the stacks at the front face the stack. Stacks were placed next to each other without any gaps and each tray is similar in shape and size within a stack. Therefore, it was sufficient to model only one row of eggs in a tray within a stack. The experimental validation was conducted for one tray, and the temperatures were measured on eggs only along the central row of the tray.

Development of a CFD model for simulation of heat transfer within an egg and fluid flow outside the egg is complex due to the geometric intricacy of a tray containing the eggs. The geometric model of egg trays for one row is shown in Fig. 1B. As the rows were similar, a single row containing five eggs of uniform size with the top and bottom trays were considered in the CFD model, assuming that all other rows were exposed to the same boundary conditions. The bottom surface of the bottom tray and the top surface of the top tray were filled with GreatStuff ${ }^{\circledR}$ polyurethane foam (Dow Chemical Company, USA) to form a smooth and level surface to avoid air leakage. Geometries of the top and the bottom tray were created in STL (ASCII) format using Solidworks CAD software and imported to the PHOENICS software environment (Fig. 1C). Figure 1c shows the space available above and the sides of the egg for air flow. The computational domain of the CFD model included a single row of top and bottom layers of an egg tray filled with 5 eggs, inlet and outlet of the test chamber. Grade A eggs $(44 \times 44 \times 58 \mathrm{~mm})$ were considered for investigation in this study. The ovoid shape of shell egg was considered as a spheroid for geometry simplification $(\mathrm{Ku}-$ mar et al., 2009).

\subsubsection{Governing equations}

The flow field in the computational domain was obtained by solving 3-D continuity and momentum equations in 3-D. A k- $\varepsilon$ turbulent model (Launder and Spalding, 1974) was used to model the Reynolds stress component in the momentum equation by solving 3-D equations for turbulent kinetic energy and turbulent energy dissipation rate in 3-D. The energy equation was solved to compute transient egg temperature under forced convection cooling/heating condition in 3-D. The governing equations in Cartesian -tensor form are (Li et al., 2009, Kumar et al., 2009):

Continuity: The governing mass conservation equation for incompressible fluid would be as follows:

$$
\frac{\partial}{\partial \mathbf{x}_{\mathrm{j}}}\left(\rho \mathrm{U}_{\mathrm{j}}\right)=0
$$

Equation (1) implies that the mass flow rate of air entering one side of the pallet must be equal to that of the air leaving the other side of the pallet.

Momentum: The governing momentum conservation equation in three directions, viz., $\mathrm{x}, \mathrm{y}$, and $\mathrm{z}$ would be as follows:

$$
\frac{\partial}{\partial x_{j}}\left(\rho U_{i} U_{j}\right)=-\frac{\partial p}{\partial x_{i}}+\frac{\partial}{\partial x_{j}}\left(\mu\left(\frac{\partial U_{i}}{\partial x_{j}}+\frac{\partial U_{j}}{\partial x_{i}}\right)-\left(\rho u_{i}^{\prime} u_{j}^{\prime}\right)\right)
$$

Equation (2) states that the momentum of air is conserved at any point in the fluid domain. 


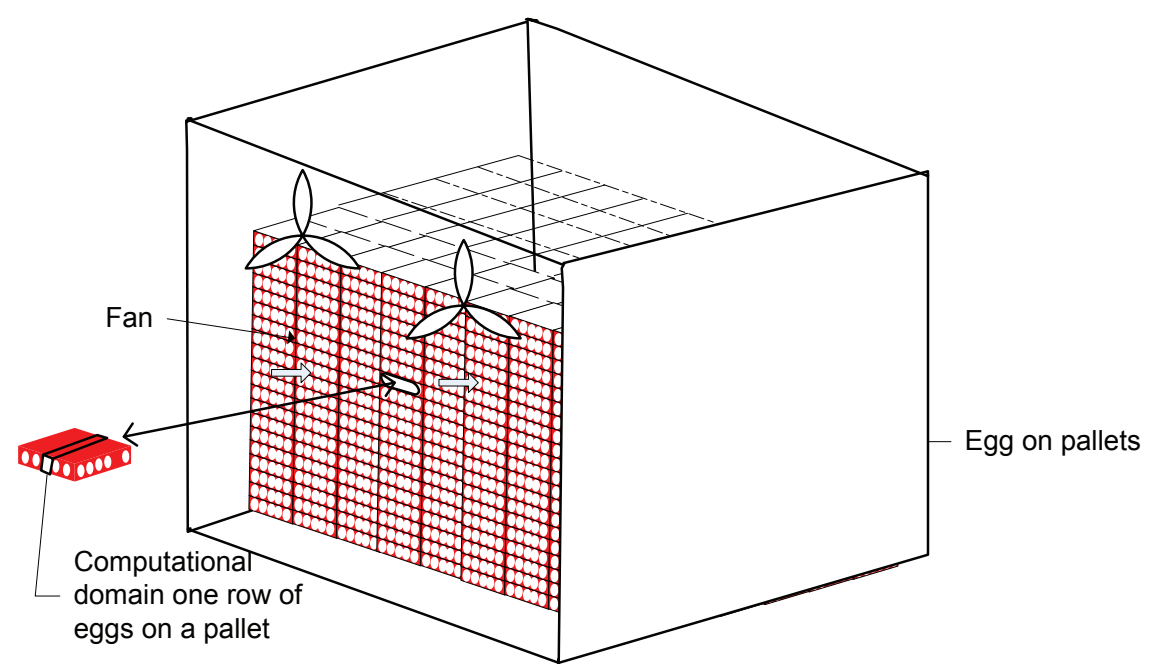

A. Stacking of eggs on plastic pallets in cooling room

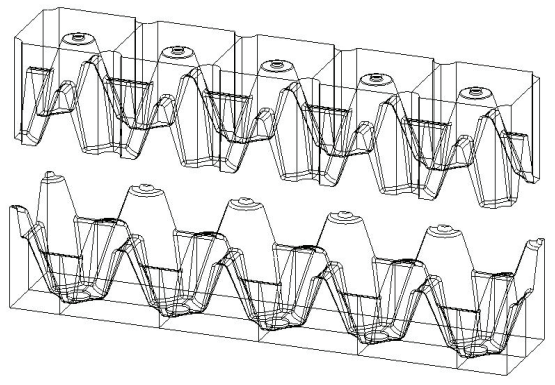

B. A wireframe model of one row of top and bottom egg tray

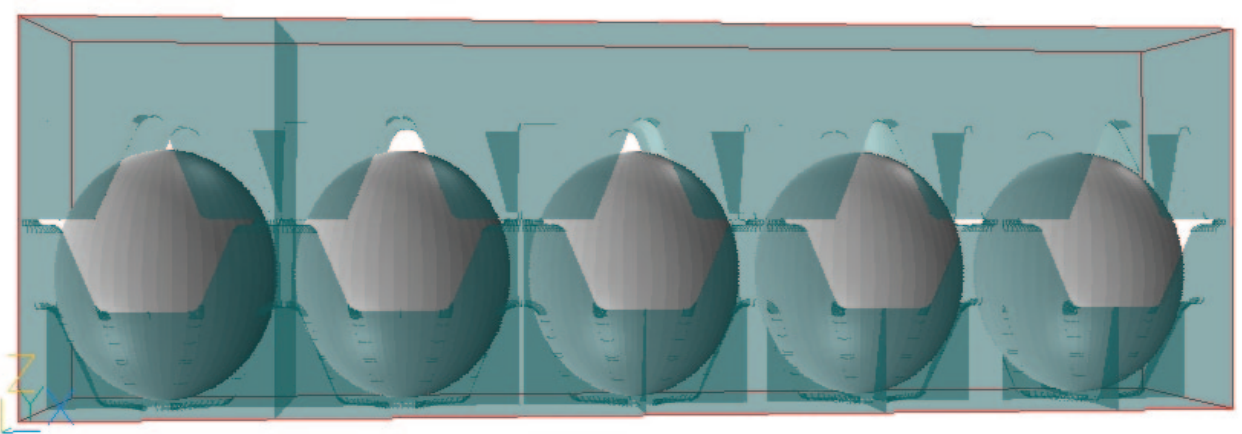

C. Geometric model of eggs placed on plastic tray row

Fig. 1. A geometric model of five eggs packed in top and bottom egg trays.

Even though the air velocity before entering the tray is very low, the space between the eggs in an egg tray is extremely small. Air velocity then increases as it moves through the tray, leading to a large Reynolds number $(4,888$ to 16,948$)$. Therefore, the turbulence $(\mathrm{k}-\varepsilon)$ model was used. The Reynolds stress is modeled based on Boussinesq hypothesis using standard k- $\varepsilon$ model, which solved transport equations for the turbulent kinetic energy and its dissipation rate. The model is stable, numerically robust, less computational expensive and it has established regime of predictability for internal flow in industrial applications (Pham, 2001). Its selection was guided by the above considerations.

$$
-\rho \overline{\mathrm{u}_{\mathrm{i}}^{\prime} \mathrm{u}_{\mathrm{j}}^{\prime}}=\mu_{\mathrm{t}}\left(\frac{\partial \mathrm{U}_{\mathrm{i}}}{\partial \mathrm{x}_{\mathrm{j}}}+\frac{\partial \mathrm{U}_{\mathrm{j}}}{\partial \mathrm{x}_{\mathrm{i}}}\right)-\frac{2}{3} \mathrm{k} \delta_{\mathrm{j}}
$$

The transport equations for $\mathrm{k}$ and $\varepsilon$ are

$$
\begin{aligned}
& \frac{\partial}{\partial \mathrm{t}}(\rho k)+\frac{\partial}{\partial \mathrm{x}_{\mathrm{i}}}\left(\rho \mathbf{V}_{\mathrm{i}}\right)=\frac{\partial}{\partial \mathrm{x}_{\mathrm{j}}}\left[\left(\mu+\frac{\mu_{\mathrm{t}}}{\sigma_{\mathrm{k}}}\right) \frac{\partial \mathrm{k}}{\partial \mathrm{x}_{\mathrm{j}}}\right]+\mathrm{G}_{\mathrm{k}}-\rho \\
& \frac{\partial}{\partial \mathrm{t}}(\rho \varepsilon)+\frac{\partial}{\partial \mathrm{x}_{\mathrm{i}}}\left(\rho \varepsilon \mathrm{U}_{\mathrm{i}}\right)=\frac{\partial}{\partial \mathrm{x}_{\mathrm{j}}}\left[\left(\mu+\frac{\mu_{\mathrm{t}}}{\sigma_{\varepsilon}}\right) \frac{\partial \varepsilon}{\partial \mathrm{x}_{\mathrm{j}}}\right]+\mathrm{C}_{1 \varepsilon} \mathrm{G}_{\mathrm{k}} \frac{\varepsilon}{k}-\mathrm{C}_{2 \varepsilon} \rho \frac{\varepsilon^{2}}{k}
\end{aligned}
$$

Turbulent viscosity

$$
\mu_{\mathrm{t}}=\rho \mathrm{C}_{\mu} \frac{\mathrm{k}^{2}}{\varepsilon}
$$
where, $G=-\rho \mathrm{u}_{\mathrm{i}}^{\prime} \mathrm{u}_{\mathrm{j}} \frac{\partial \mathrm{U}_{\mathrm{j}}}{\partial \mathrm{x}_{\mathrm{i}}} \quad$ represents production of turbulent kinetic
energy

In the above equations, $\mathrm{C}_{\mu}, \sigma_{\mathrm{k}}, \sigma_{\varepsilon}, \mathrm{C}_{1 \varepsilon}$, and $\mathrm{C}_{2 \varepsilon}$ are constant and their respective values are $0.09,1.0,1.314,1.44$, and 1.92 ( $\mathrm{Li}$ et al., 2009, PHOENICS 2008). 
Energy: The governing energy conservation equation for transient heat transfer under forced convection would be as follows:

$$
\rho C_{p} \frac{\partial T}{\partial t}+\rho U_{j} C_{p} \frac{\partial T}{\partial x_{j}}=\frac{\partial}{\partial x_{j}}\left[\lambda_{e f f} \frac{\partial T}{\partial x_{j}}-\rho C_{p}\left(u_{j}^{\prime} T^{\prime}\right)\right]
$$

The above equation states that the thermal energy transferred due to fluid momentum contributes to diffusion of thermal energy within egg. Effective thermal conductivity is expressed as :

$$
\lambda_{\text {eff }}=\lambda+\mathrm{C}_{\mathrm{p}} \frac{\mu_{\mathrm{t}}}{\sigma_{\mathrm{t}}}
$$

\subsubsection{Boundary conditions}

Following boundary conditions were applied in the simulation:

\section{Flow}

1. The fluid flow was considered to be incompressible and uniform at the inlet of test chamber. The Reynolds number of fluid flow at the inlet varied from 4,888 to 16,948 under various conditions.

2. At the outer surface of egg wall and the test chamber wall, $U=$ 0 , due to no slip condition

3. In this study, the egg was cooled from $37{ }^{\circ} \mathrm{C}$ to refrigerated temperature $\left(7^{\circ} \mathrm{C}\right)$. In this temperature range, the movement of liquid egg components due to temperature gradient was assumed to be negligible inside the egg, therefore in the egg domain, $\mathrm{U}=0$.

4. Uniform average velocity was assigned at inlet of the test chamber, $\mathrm{U}=\mathrm{U}_{\mathrm{avg}}$. At the inlet, the turbulent intensity was specified as $5 \%$ and the turbulent length scale was taken as $5 \%$ of inlet height (ESI 2010, PHOENICS 2008, CFD wiki).

5. At the outlet, $\mathrm{P}=\mathrm{P}_{0}$ (atmospheric pressure).

\section{Thermal}

1. The egg and the egg tray were assumed to be at uniform initial temperature, $\mathrm{T}=\mathrm{T}_{\mathrm{i}}$.

2. For constant inlet temperature simulation, $T=T_{a}$. The fluid temperature was measured at three locations of inlet plane and the average temperature value was assigned.

3. For variable inlet temperature of fluid, it was specified as $\mathrm{T}=$ $\mathrm{T}_{1}, \mathrm{~T}_{2}, \mathrm{~T}_{\mathrm{n}}$ at different time, viz., $\mathrm{t}=\mathrm{t}_{1}, \mathrm{t}_{2}, \mathrm{t}_{3}, \ldots \mathrm{t}_{\mathrm{n}}$.

4. Adiabatic boundary condition was specified at the walls of test chamber, as the walls of the test chambers were well insulated.

\subsubsection{Solution strategy}

Equations (1-8) were solved using PHOENICS, a finite volume based CFD software. The software uses structured grid and the solution method is based on SIMPLEST algorithm (Spalding 1980). This algorithm is a variant of SIMPLE (Semi-Implicit Method for Pressure-Linked Equations) and produces smooth convergence.

For the simulation, the tray and the foam were considered to be made up of a composite material with homogeneous properties. The reason for this assumption was that the modeling was done using structured grids and it was extremely difficult to resolve the small thickness $(\sim 1 \mathrm{~mm})$ of plastic tray material with structured grid. Choi and Okas (1986) method was used to obtain the composite properties of tray and foam and was used in the model. An egg consists of shell, albumen, and yolk. For the CFD model, the egg was considered to be a homogenous solid with composite properties of shell, albumen, and yolk. The reason for this simplification was to make the computation faster. For resolving the thickness of the shell in numerical simulation, very fine structured grids would be required in the egg region, which would be very computationally expensive. Although the albu- men is in liquid stage, it was assumed that there would not be any significant fluid flow at lower temperatures within the egg, which eliminated solution of additional variables for liquid flow within egg, and the albumen was assumed as solid for heat transfer calculation. By not considering fluid flow within the egg, the computation was considerably reduced. Sabliov et al., (2002) has also made the similar simplification in their study by considering egg as a single composite entity, taking into account these considerations with equivalent thermo - physical properties for reducing the computational grid and solution time.

The egg and the plastic trays were modeled individually as composite materials with their equivalent thermo-physical properties (Choi and Okos, 1986; Kumar et al., 2009). The thermo-physical properties of the egg and egg tray were assumed to be constant except for the specific heat of egg (Table 1A). Turbulence model $(k-\varepsilon)$ was used for modeling turbulent flow over eggs within tray. Heat transfer inside the egg and within plastic tray was assumed mainly due to conduction and at the outer surface due to forced convection. Free convection inside the egg was not considered due to minor variation in density of yolk and albumen at lower temperature (Kumar et al., 2009).

For discretizing computational domain $(508 \times 50 \times 90 \mathrm{~mm})$, structured grids were used as shown in Fig. 2. A mesh-independence study was conducted and found that 68,355 brick elements were sufficient, when the temperature difference between air and egg was small in case of concurrent-heating and concurrent-cooling experiments (explained in the section 2.4). In case of pre-chilled cooling experiments, where the temperature difference between egg and air was large, 543,400 brick elements were found to be sufficient for mesh-independence study. In general, cell size in air, egg and tray domains were 2.7 $\times 1.3 \times 1.6,1.8 \times 1.3 \times 1.6 \mathrm{~mm}$, and $1.2 \times 1.3 \times 1.6 \mathrm{~mm}$, respectively. For resolving fluid flow around the eggs, finer meshes with 16 and 2 additional grids were inserted over the above and below the eggs, respectively. The value of dimensionless wall distance, $\mathrm{Y}^{+}$, in the computational domain varied in the range of 0 to 45 . The grids were discretized using hybrid scheme. The computations of partially cut cells at the curved edges of eggs and trays were done by using Cartesian cut-cell method, which identifies fluid and solid in partially cut grids using two-dimensional-section method to improve the accuracy of simulation (PHOENICS 2008). It computes accurately the wall surface area and the distance normal to the wall surface.

The model uses equilibrium log-law wall functions to compute fluid flow and heat transfer near wall region. In case, the near-wall Reynolds number falls below the transition value of 132, the wall functions revert to laminar flow for momentum and heat. For the turbulence variables, the near-wall dissipation rate is computed from the minimum of $\varepsilon_{\log }$, and $\varepsilon_{\lim }$. Where $\varepsilon_{\log }$ is the value of $\varepsilon$ in the turbulent region determined as (PHOENICS, 2008):

$$
\varepsilon_{\log }=\frac{u_{f}^{3}}{\mathrm{~K}_{\text {distw }}}
$$

$\varepsilon_{\lim }$ the value of $\varepsilon$ that approximately prevails at the edge of the viscous sub layer and it is determined as:

$$
\varepsilon_{\lim }=\frac{u_{f}^{4}}{v}
$$

where $v$ is kinematic viscosity and $\mathrm{u}_{\mathrm{f}}$ is the frictional velocity.

Momentum and energy equations were decoupled to reduce computation time (Kumar et al., 2009). First, steady state flow field was obtained by solving continuity and momentum equations. The flow field should not change considerably during the cooling time, as the range of temperature $\left(37\right.$ to $\left.7^{\circ} \mathrm{C}\right)$ used in the simulation has negligible effect on properties of air (Table 1B). Therefore, it is sufficient to solve for flow field at the beginning of the simulation and use that 


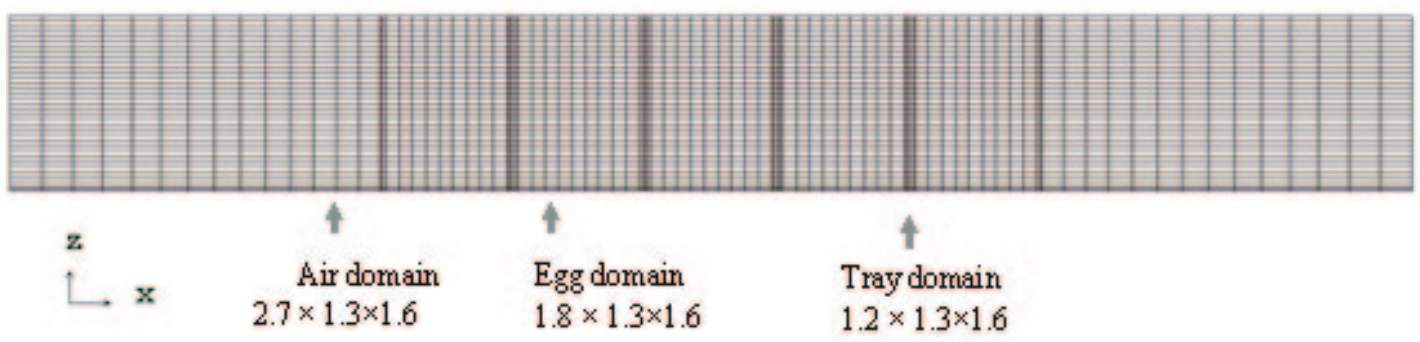

Fig. 2. Grid size distribution in a computational domain consisting of a top and a bottom egg tray with five eggs.

Table 1A. Thermo-physical properties of egg components and egg tray

\begin{tabular}{|c|c|c|c|c|c|c|c|}
\hline \multirow[t]{2}{*}{ Properties } & \multirow[t]{2}{*}{ Shell ${ }^{\$}$} & \multirow[t]{2}{*}{ Albumen $\$$} & \multirow[t]{2}{*}{ Yolk $^{s}$} & \multirow[t]{2}{*}{ Composite egg } & \multirow[t]{2}{*}{ Foam } & \multicolumn{2}{|c|}{ Egg tray } \\
\hline & & & & & & Single & Multiple \\
\hline Density $\left(\mathrm{kg} / \mathrm{m}^{3}\right)$ & 1270 & 1010 & 1040 & 1037 & 136.3 & 66 & 1059 \\
\hline Specific heat $(\mathrm{J} / \mathrm{kg}-\mathrm{K})^{*}$ & $548-892$ & $1461-3472$ & $1032-2724$ & $2366-2768$ & 1400 & 1133 & 3050 \\
\hline
\end{tabular}

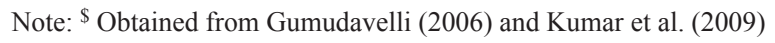

* Specific heat capacity was determined at mean temperature of initial and final egg temperature

Table 1B. Thermo-physical properties of air (Cengel 2007)

\begin{tabular}{lllll}
\hline $\begin{array}{l}\text { Temperature } \\
{ }^{\circ} \mathrm{C}\end{array}$ & $\begin{array}{l}\text { Density } \\
\mathrm{kg} / \mathrm{m}^{3}\end{array}$ & $\begin{array}{l}\text { Specific heat } \\
\mathrm{J} / \mathrm{kg}-\mathrm{K}\end{array}$ & $\begin{array}{l}\text { Thermal } \\
\text { Conductivity } \\
\mathrm{W} / \mathrm{m}-\mathrm{K}\end{array}$ & $\begin{array}{l}\text { Kinematic } \\
\text { viscosity, } \\
\mathrm{m}^{2} / \mathrm{s}\end{array}$ \\
\hline 5 & 1.269 & 1006 & 0.02401 & $1.382 \times 10^{-5}$ \\
10 & 1.246 & 1006 & 0.02439 & $1.426 \times 10^{-5}$ \\
15 & 1.225 & 1007 & 0.02476 & $1.470 \times 10^{-5}$ \\
20 & 1.204 & 1007 & 0.02514 & $1.516 \times 10^{-5}$ \\
25 & 1.184 & 1007 & 0.02551 & $1.562 \times 10^{-5}$ \\
30 & 1.164 & 1007 & 0.02588 & $1.608 \times 10^{-5}$ \\
35 & 1.145 & 1007 & 0.02625 & $1.655 \times 10^{-5}$ \\
\hline
\end{tabular}

steady-state steady flow field for solving the transient temperature of eggs during forced convection cooling or heating condition. Decoupling reduces the computation time drastically.

The following convergence criteria were considered for converged solutions:

1. Source balance (a discrepancy between sum of incoming fluxes and sum of outgoing fluxes $<1 \%$ ).

2. Stabilization of spot values in a representative region of the domain after errors were minimized (difference in successive iteration is less than $0.1 \%$ ).

3. Reduction of residual errors of solved variables by at least a factor of 100 from the value after the initial few iterations.

\subsubsection{Experimental setup and methodology}

A wind tunnel was used for thermal validation studies (cooling/heating) of multiple eggs placed on an egg tray. The wind tunnel consisted of a chiller (6106, Polyscience, Niles, USA), heat exchanger (Nationwide Coils, New York, USA), an axial fan (AF18-3, Caldwell, Kearney, USA), and a test chamber (Fig. 3). A pair of top and bottom egg trays with 30 eggs ( 6 rows and 5 columns) was placed in the test chamber $(508 \times 300 \times 85 \mathrm{~mm})$. Six T-type thermocouples (Model: HTTC48-T-116G-1 1/2", Omega Engineering, Inc., Stamford, CT) were inserted in six eggs close to the geometric centers to monitor yolk temperature of eggs located on the first, third and fifth egg of the $3^{\text {rd }}$ and $4^{\text {th }}$ row of the tray as shown in Fig. 4. At the end of the experiment, the eggs with thermocouples were cooked in boiling water and exact location of thermocouple inside the egg was determined for each egg. The egg temperatures from the finite volume grid corresponding to that physical location of thermocouple in the egg were extracted from the simulations and compared with the experimental readings. Egg yolk temperatures measured by the thermocouples placed on $1^{\text {st }}, 3^{\text {rd }}$, and $5^{\text {th }}$ egg on two $\left(3^{\text {rd }}\right.$ and $\left.4^{\text {th }}\right)$ rows of eggs were averaged for each egg which was used for validation of CFD model. One thermocouple was fixed at the surface of the top egg tray and the other one at the bottom surface of the egg tray. Temperature data were logged every $20 \mathrm{~s}$ using a data acquisition system (USB-TC, Measurement Computing, Norton, USA). Three cylindrical ducts were provided in the test chamber through $10 \mathrm{~mm}$ diameter holes for inserting anemometer as shown in Fig. 5. The air velocity was measured at different heights in a vertical plane at the inlet of the test chamber using a hot wire anemometer (Model 425, Testo, Germany, resolution: $\pm 0.03 \mathrm{~m} / \mathrm{s}$, accuracy: $5 \%$ of reading). The different measurements were averaged for computing average inlet air velocity and temperature, which were then used in simulation studies.

Experiments were conducted under three different conditions. These conditions vary on the initial temperature of egg and air.

a. Concurrent Cooling: In concurrent cooling, the initial conditions of eggs and wind tunnel (air) were at room temperatures. Because it took several hours to cool the wind tunnel, the eggs and air were concurrently cooled. This is a worst case cooling scenario in the egg industry, where the eggs were moved to the chiller and then the power for the cooling system was switched on. To conduct this experiment, eggs were placed at room temperature for $6 \mathrm{~h}$ prior to being placed in the test chamber to equilibrate to room temperature $\left(24-25^{\circ} \mathrm{C}\right)$, while the fans and chilling system for the wind tunnel was not operating. The eggs were then placed in the wind tunnel and chilling system was started to cool both test chamber and the eggs simultaneously to $7^{\circ} \mathrm{C}$.

b. Concurrent Heating: It was aimed at studying the temperature rise in eggs due to failure of cooling equipment which might lead to bacterial growth. During the experiment, the chiller was switched off after completion of the cooling cycle while the axial fan was kept on running to recirculate the same air. It resulted in an increase of inlet air temperature over the period of time due to heat transfer from surrounding to the air inside the wind tunnel and the eggs reached ambient temperature.

c. Pre-chilled cooling: It was aimed at studying the cooling behavior of freshly laid eggs at $37 \pm 1{ }^{\circ} \mathrm{C}$ while transported to 


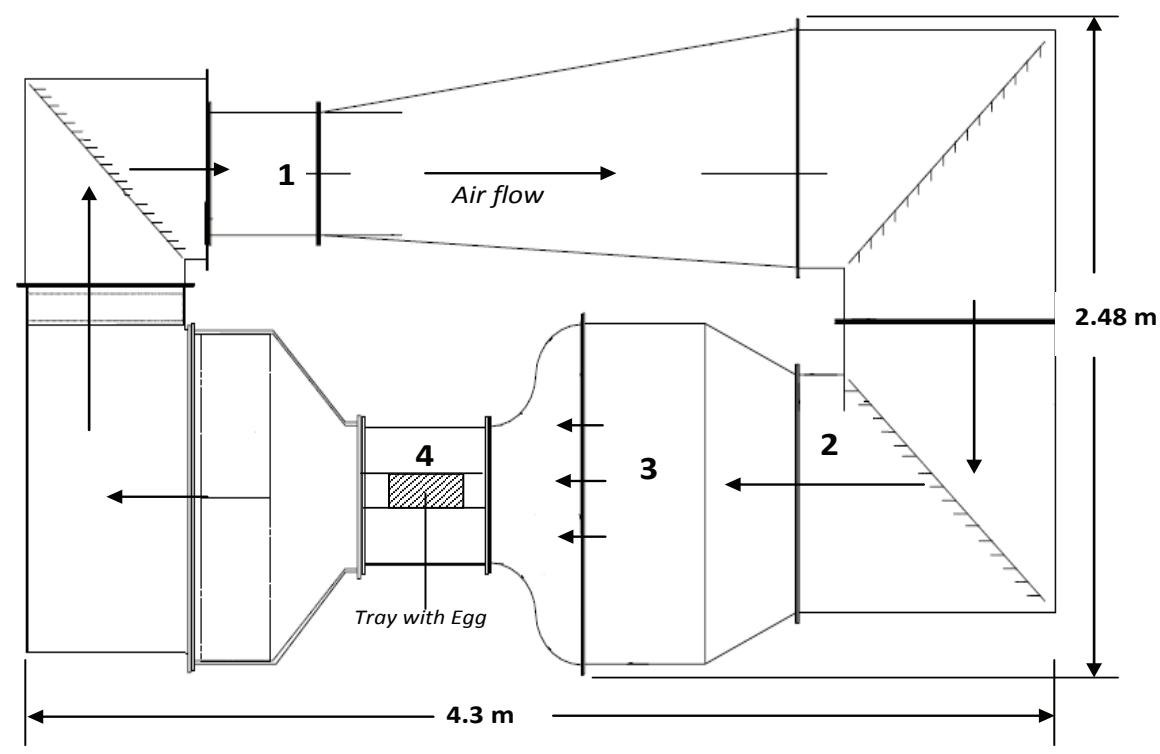

Fig. 3. Schematic diagram of wind tunnel (1. Axial fan 2. Heat exchanger 3. Flow straightener 4. Test Chamber).

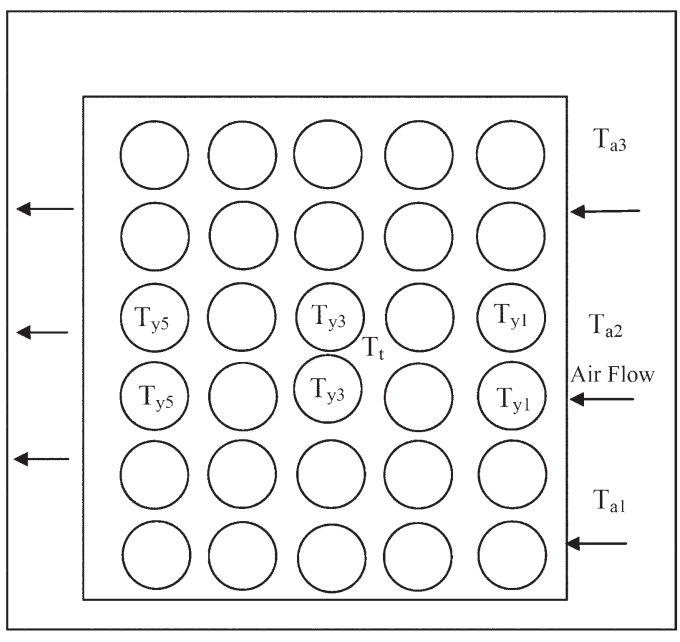

Fig. 4. Location of thermocouples for monitoring yolk temperature of of eggs $\left(T_{\mathrm{y}}\right)$ inlet air $\left(T_{\mathrm{a}}\right)$ and tray $\left(T_{\mathrm{t}}\right)$.

pre-chilled rooms at $5-7{ }^{\circ} \mathrm{C}$. To replicate this condition, eggs were preheated in an oven (DPC 400, Hybaid Limited, UK) for $4 \mathrm{~h}$ at $37 \pm 1{ }^{\circ} \mathrm{C}$. The cooling system in the wind tunnel was switched on for few hours so that the test chamber of the wind tunnel was pre chilled to $5-7^{\circ} \mathrm{C}$, prior to experiments.

The developed CFD model simulated the temperature at the center of the egg placed at $1^{\text {st }}, 3^{\text {rd }}$, and $5^{\text {th }}$ positions at each time step for the afore-mentioned scenarios. The experimental data were used to validate the model. The accuracy of the model was assessed by determining root mean squared error (RMSE) as below:

$$
\text { RMSE }=\sqrt{\frac{\sum_{\mathrm{i}=1}^{\mathrm{n}}\left(\mathrm{T}_{\mathrm{O}}-\mathrm{T}_{\mathrm{P}}\right)^{2}}{\mathrm{~N}}}
$$

where, $T_{P}$ is simulated temperature and $T_{0}$ is measurement temperature at time $\mathrm{t}$.

\subsection{Simulation and experimentation with multiple trays (Obj. 2)}

In the shell egg industry, the eggs are stacked together in multiple egg trays. To simulate this case, the CFD model developed for a single egg tray was modified to validate the egg cooling in multiple

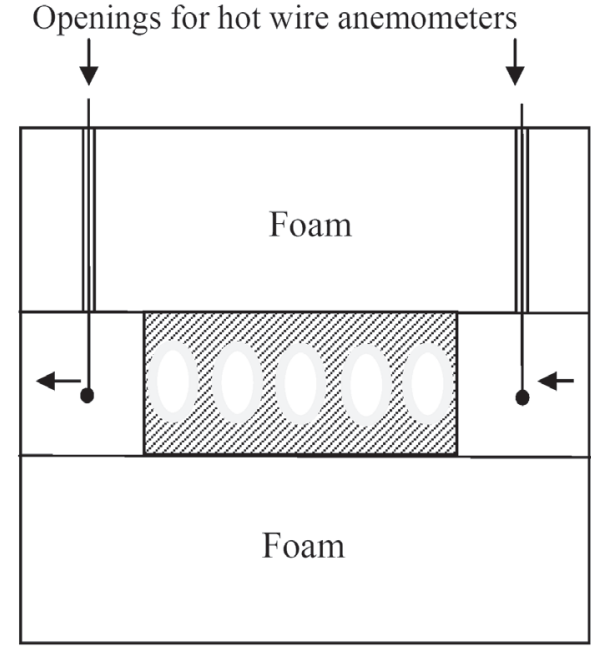

Fig. 5. A schematic diagram of test chamber.

trays. The experimental setup earlier explained was modified to accommodate three sets of egg trays. The top and the bottom egg trays (Fig. 1B) were filled with foam to prevent air leakage as explained in the single egg tray study, whereas in the middle, two standard plastic egg trays were used. Egg center temperatures of first (egg 1), third (egg 3), and fifth (egg 5) were monitored in the third and fourth row of the middle egg tray to validate the model, assuming uniform air flow at each tray. The CFD model for the single egg tray was slightly modified. The top and bottom egg trays were assumed to be composed of egg and egg tray material (plastic) of similar shape and dimension as used in the single egg tray study and accordingly, the equivalent thermo-physical properties were computed. The density, specific heat and thermal conductivity of equivalent egg tray material were calculated and reported in Table $1 \mathrm{~A}$.

The objective of this part of validation is to evaluate the performance of the single tray CFD model expanded to predict temperature distribution in multiple trays. The same grid and the experimental procedure were adopted as used in the case of pre-chilled cooling for single egg tray. The predicted model results were compared with experimental results obtained for pre-chilled cooling at inlet air velocities of $0.4 \mathrm{~m} / \mathrm{s}$ and $1.04 \mathrm{~m} / \mathrm{s}$ to validate the CFD model. 


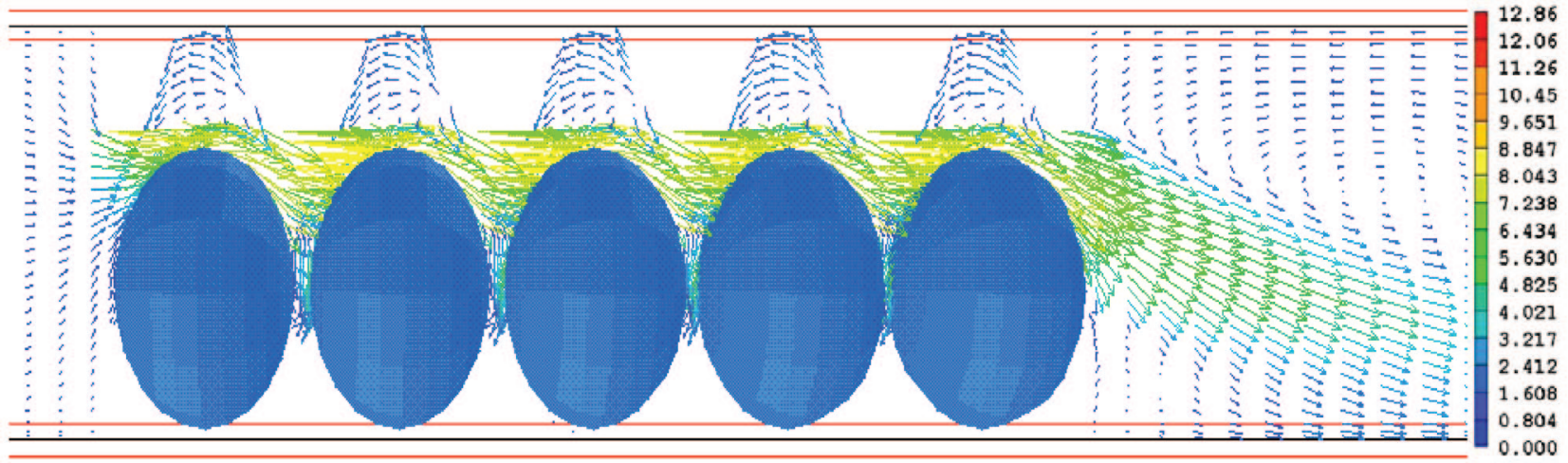

Fig. 6. Velocity profile over eggs predicted by CFD model at an air velocity of $0.6 \mathrm{~m} / \mathrm{s}$ under concurrent cooling.

\subsection{Microbial growth prediction (Obj. 3)}

To evaluate performance of the heat transfer model, RMSE was used. However, RMSE does not explain the risk of SE growth. To quantify the model error in terms of SE growth, the observed and predicted temperature profiles were fed as an input to the SE microbial growth model developed by Gumudavelli (2006) and the error in terms of microbial growth at the end of chilling period was determined.

From a food safety standpoint, the egg yolk is the slowest cooling region. In addition, the potential for SE growth would be higher in egg yolk compared to the albumen due to better nutrient availability in egg yolk and presence of natural antimicrobials such as lysozyme in albumen. Gumudavelli et al. (2007b) developed a dynamic microbial growth model as described by Baranyi and Roberts (1994):

$$
\begin{gathered}
\frac{d y}{d t}=\frac{1}{1+e^{-Q}} \mu_{\max }\left(1-e^{\left(y-y_{\max }\right)}\right) \\
\frac{d Q}{d t}=\mu_{\max }
\end{gathered}
$$

with initial conditions $d t y_{o}$ at $\mathrm{t}=0$ and $Q=\log _{\mathrm{e}}\left(q_{o}\right)$ where $q_{o}$ is a measure of the initial physiological state of cells, $y_{o}$ is initial cell concentration in $\log \mathrm{CFU} / \mathrm{g} ; y_{\max }$ is maximum cell concentration in $\log _{\mathrm{e}} \mathrm{CFU} / \mathrm{g}$; $\mu_{\text {max }}$ is maximum specific growth rate in terms of $\log _{\mathrm{e}} \mathrm{CFU} / \mathrm{g}$ in $1 / \mathrm{h}$. At isothermal conditions, the Equation 10 and 11 can be analytically solved. Gumudavelli et al. (2007b) obtained the growth kinetics data at various isothermal conditions and determined the growth rate at various temperatures. Then, a secondary model based on modified Ratkowsky equation (Zwietering et al., 1991) was developed:

$$
\mu_{\max }=0.002065(T-6.13)^{2} \cdot(1-\exp (0.27469(T-46.26)))
$$

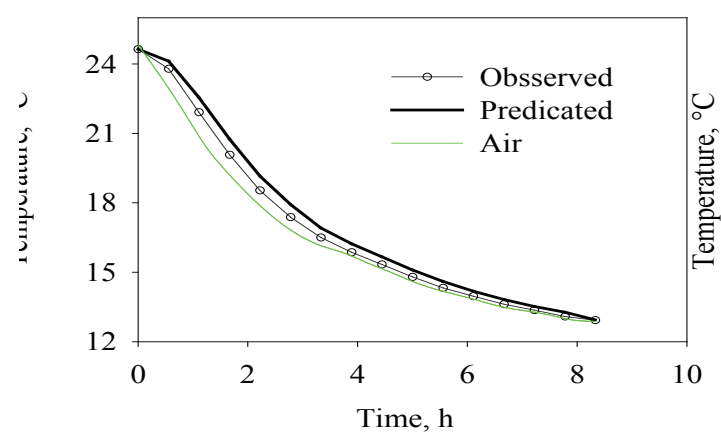

a) Upstream egg

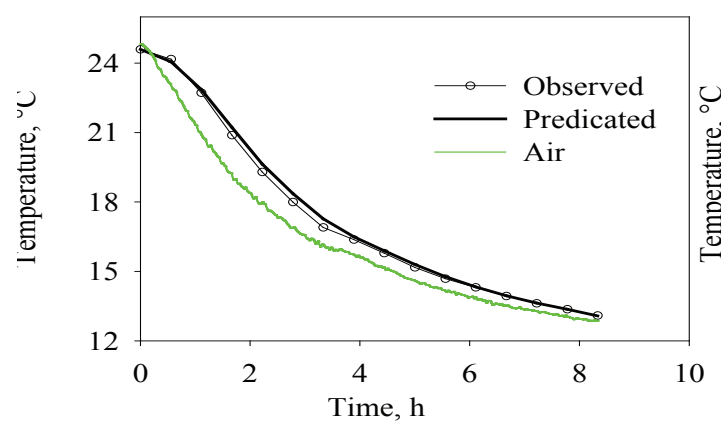

c) Downstream egg

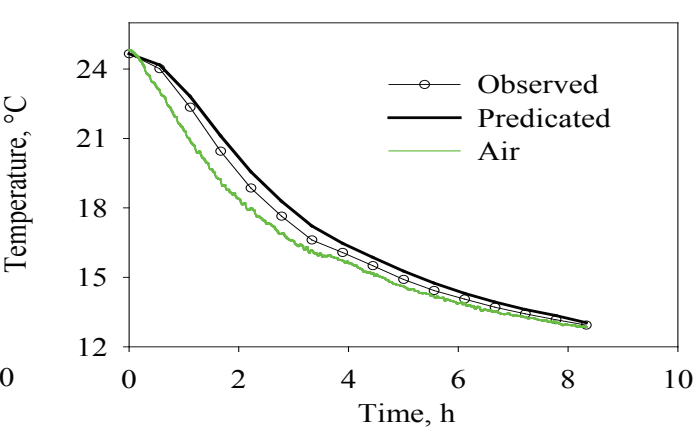

b) Midstream egg

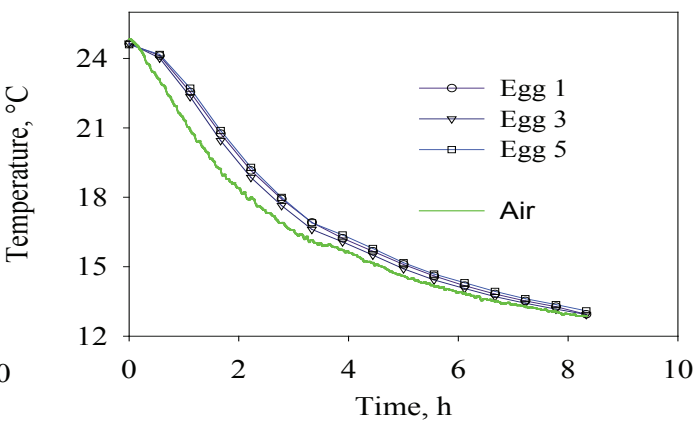

d) Effect of egg location

Fig. 7. Predicted and observed egg yolk temperature of eggs subjected to concurrent cooling at $0.6 \mathrm{~m} / \mathrm{s}$ air velocity. 


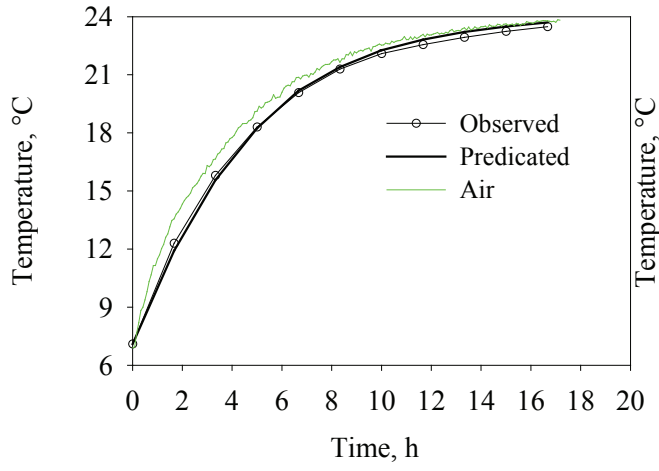

a) Upstream egg

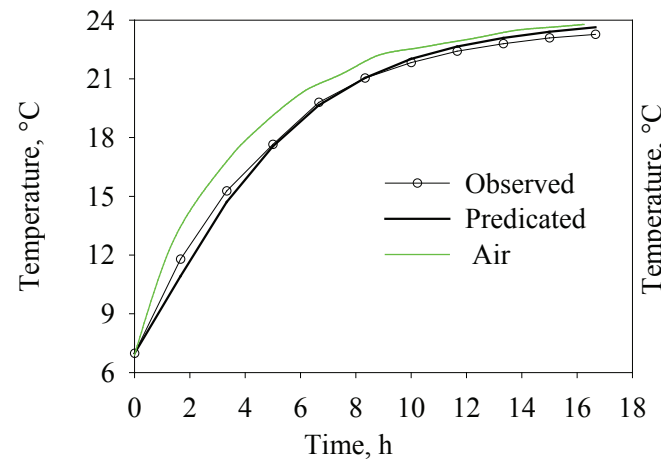

c) Downstream egg

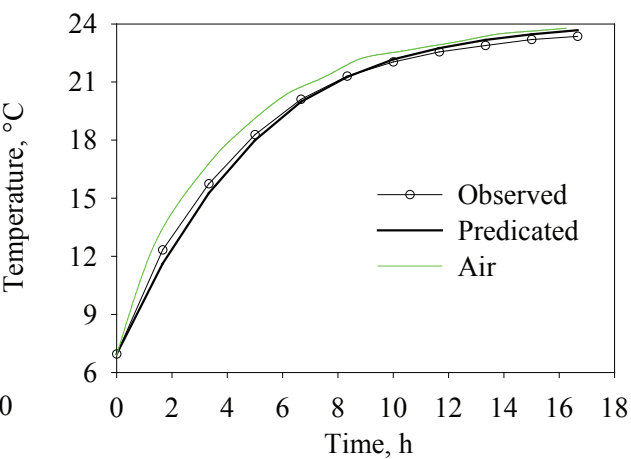

b) Midstream egg

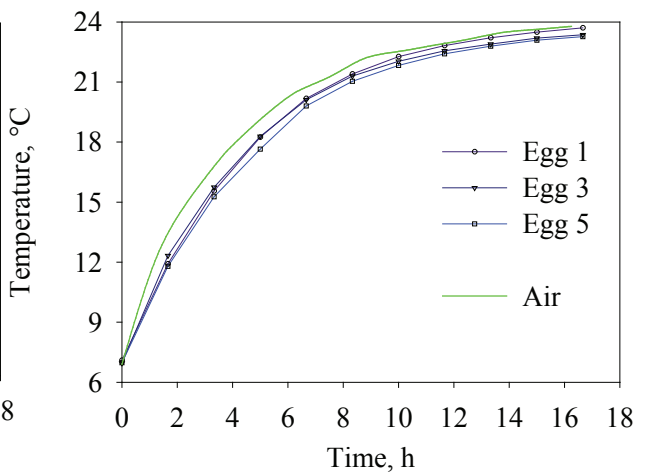

d) Effect of egg location

Fig. 8. Predicted and observed egg yolk temperature of eggs subjected to concurrent heating with $0.5 \mathrm{~m} / \mathrm{s}$ air velocity.

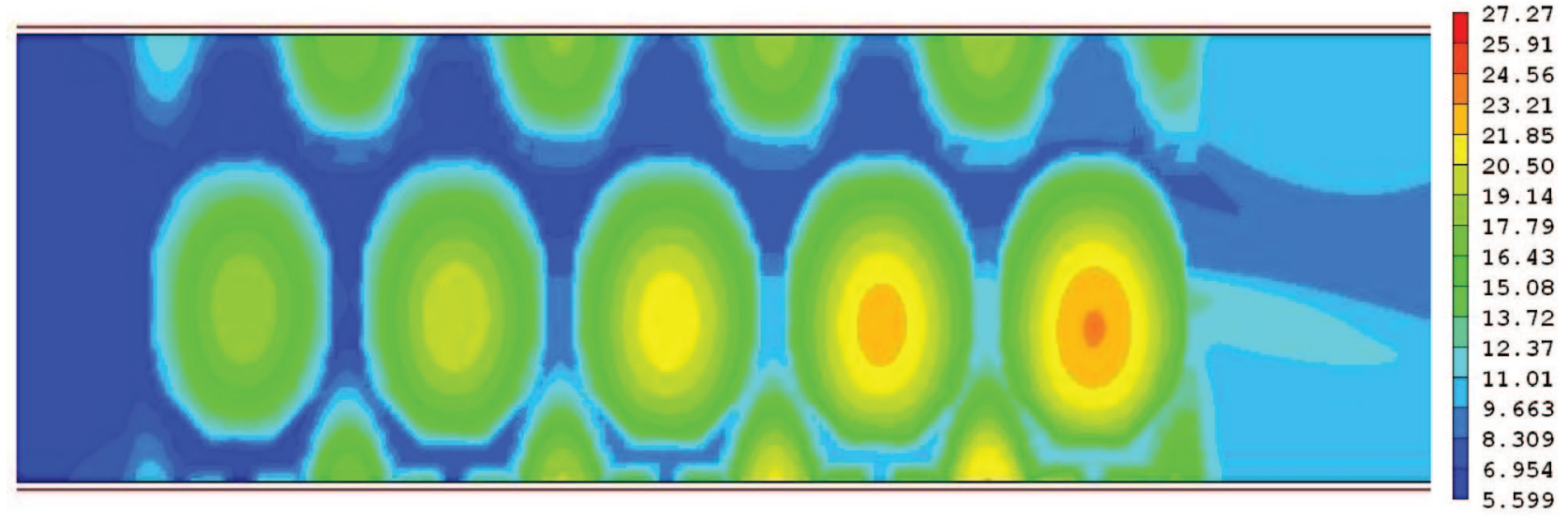

Fig. 9. Temperature contour of eggs after $1200 \mathrm{~s}$ of cooling at an air velocity of $0.6 \mathrm{~m} / \mathrm{s}$.

For dynamic model, the Eq. 14 was numerically integrated with Eqs. 12 and 13 by Range-Kutta fourth order method in Matlab software. For each cooling scenario, the transient egg yolk temperature profile from the CFD model and the experiments was used as an input into Eq 14 and then numerically integrated to estimate SE growth during cooling. An initial SE concentration of $1 \mathrm{log} \mathrm{CFU} / \mathrm{g}$ of SE was used to predict the growth of the SE. The difference in predicted SE growth based on observed and predicted temperature profile was determined to assess the performance of the heat transfer model.

\section{Results and Discussions}

Initially, the fluid flow solution was obtained under steady state in the CFD model. The velocity profile (Fig 6) reveals that most of the air passed over the top portion of the eggs at higher velocity due to sudden reduction in available area for air flow. There is a slight air- flow on the sides of egg, while there was negligible airflow below the eggs (Fig 6). This would result in forced convective heat transfer predominant at the top portion of the eggs. A small amount of

Table 2. Summary of RMSE predicted by CFD model at different velocities under concurrent heating

\begin{tabular}{llllll}
\hline Velocity $\mathrm{m} / \mathrm{s}$ & \multicolumn{2}{l}{ RMSE, ${ }^{\circ} \mathrm{C}$} & & \multicolumn{2}{c}{ Time, $\mathrm{h}$} \\
\cline { 2 - 6 } & Upstream & Midstream & Downstream & Overall \\
\hline 0.3 & 0.18 & 0.26 & 0.29 & 0.25 & 19 \\
0.4 & 0.22 & 0.38 & 0.42 & 0.35 & 17 \\
0.5 & 0.22 & 0.32 & 0.38 & 0.32 & 17.2 \\
0.6 & 0.25 & 0.67 & 0.49 & 0.50 & 16.6 \\
0.7 & 0.34 & 0.36 & 0.28 & 0.32 & 23.9 \\
\hline
\end{tabular}


air is recirculated at the top portion of each egg in which a cavity is formed between top portion of the egg and top tray.

The fluid flow computation took around 9 hours and energy calculation required took around 15 hours on Dell Precision 690 workstation with 8 GB RAM and dual Intel Xeon Processor@2.33 GHz.

\subsection{Simulation and experiment with single egg tray}

\subsubsection{Concurrent cooling}

In concurrent cooling experiments, the test chamber and the egg were at room temperature at the beginning of the experiment. Even though the refrigeration system was programmed to cool the air to 7 ${ }^{\circ} \mathrm{C}$, it took several hours for the refrigeration system to cool the air to reach the set temperature. While the air was being cooled, the egg temperatures closely followed the temperature of the air.

Using the steady state flow field solution obtained at $0.6 \mathrm{~m} / \mathrm{s}$, the transient egg yolk temperature was predicted by the model for $8.3 \mathrm{~h}$ of egg cooling (Fig. 7). The egg yolk temperature predicted by the model and the experimental temperature are presented in Fig. 7 a-c for upstream, midstream, and downstream eggs. The CFD model slightly over predicted egg yolk temperature but overall, the nature of cooling curves predicted by CFD model agreed well with experimental cooling curves. RMSE values for upstream, midstream and downstream were $0.24{ }^{\circ} \mathrm{C}, 0.36{ }^{\circ} \mathrm{C}$, and $0.28{ }^{\circ} \mathrm{C}$, respectively. The maximum deviation in predicting egg yolk temperature at upstream, midstream and downstream were $0.71{ }^{\circ} \mathrm{C}, 0.71{ }^{\circ} \mathrm{C}$, and $0.38^{\circ} \mathrm{C}$. The cooling curves for eggs were found to be exponential and the trend was similar to cooling of a single egg (Kumar et al., 2009).

Fig. 7d shows comparison of observed cooling profile of eggs located at upstream (egg 1), midstream (egg 3), and downstream (egg 5) obtained experimentally. It took $8.3 \mathrm{~h}$ to cool the egg center from $24.6{ }^{\circ} \mathrm{C}$ to $12.9{ }^{\circ} \mathrm{C}$ for the egg placed on upstream. A positive thermal gradient was observed in the eggs across the row during the first four hours of cooling and it reduced gradually over cooling time.

\subsubsection{Concurrent heating}

In the shell egg packing facilities, process deviations such as when a chiller is stopped for routine maintenance/failure, the air and egg temperature would increase over time due to heat conduction through the walls and respiration from egg. The increasing egg temperature would provide a favorable environment for SE growth. To

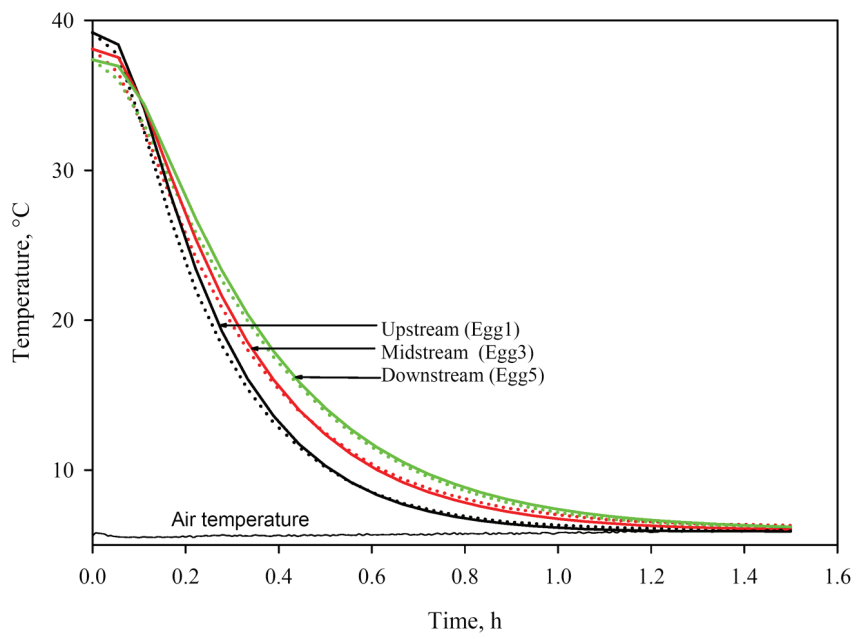

Fig. 10. Predicted (-) and observed (...) egg yolk temperature of eggs subjected to cooling in the pre-chilled wind tunnel at $0.60 \mathrm{~m} / \mathrm{s}$ air velocity. simulate this condition in the experiment, the chiller was switched off after completion of the cooling cycle thereby, allowing the egg temperature to increase over time.

To validate the CFD model under heating conditions, a simulation was carried out at $0.5 \mathrm{~m} / \mathrm{s}$ air velocity for $17.2 \mathrm{~h}$. The egg yolk temperatures predicted by the CFD model and obtained experimentally are shown in Fig. 8a-c. The CFD model slightly under predicted egg yolk temperature in the beginning and over predicted at later stage. The RMSE for predicting egg yolk temperatures by CFD model at upstream, midstream and downstream were $0.22{ }^{\circ} \mathrm{C}, 0.32{ }^{\circ} \mathrm{C}$ and $0.38^{\circ} \mathrm{C}$, respectively. The maximum deviation in the predicted and experimental egg yolk temperature were $0.42{ }^{\circ} \mathrm{C}, 0.78{ }^{\circ} \mathrm{C}$, and 1.04 ${ }^{\circ} \mathrm{C}$ for eggs placed at upstream, midstream, and downstream, respectively. Table 2. summarizes the RMSE of egg yolk temperature predicted by CFD model at various air velocities between 0.3 to $0.7 \mathrm{~m} / \mathrm{s}$. The overall RMSE ranged from 0.25 to $0.5^{\circ} \mathrm{C}$, which further corroborates that CFD model results agreed well with experimental results.

\subsection{Pre-chilled cooling}

Usually, the eggs are laid at the body temperature of the hen, transferred to storage facilities, and stored at around $7{ }^{\circ} \mathrm{C}$. To evaluate this condition, the model simulations were carried out at various air velocities $(0.36,0.46,0.54$, and $0.6 \mathrm{~m} / \mathrm{s})$ and were experimentally compared. Fig. 9 shows simulated temperature profile of eggs after $1200 \mathrm{~s}$ of cooling. As the air moved from upstream to downstream through the tray, the air became warmer and the temperature gradient between the air and egg decreased. This resulted in colder eggs in upstream, when compared to the eggs in downstream (Fig. 9). Fig. 10 shows the comparison of observed and predicted temperatures at

Table 3. A summary of RMSE predicted by CFD model at different velocities under pre-chilled cooling for $1.5 \mathrm{~h}$

\begin{tabular}{llllll}
\hline \multirow{2}{*}{$\begin{array}{l}\text { Scenario } \\
\text { type }\end{array}$} & \multirow{2}{*}{$\begin{array}{l}\text { Velocity } \\
\mathrm{m} / \mathrm{s}\end{array}$} & RMSE, ${ }^{\circ} \mathrm{C}$ & & & \\
\cline { 3 - 6 } & & & & & \\
Singleam & & Midstream & Downstream & Overall \\
\hline \multirow{4}{*}{ Multiple trays } & 0.36 & 0.54 & 0.73 & 0.53 & 0.60 \\
& 0.46 & 0.40 & 1.20 & 0.88 & 0.90 \\
& 0.54 & 0.52 & 0.42 & 0.20 & 0.40 \\
& 0.60 & 0.58 & 0.58 & 0.48 & 0.55 \\
& 0.40 & 0.42 & 0.41 & 0.34 & 0.39 \\
& 1.04 & 0.82 & 0.72 & 0.64 & 0.73 \\
\hline
\end{tabular}

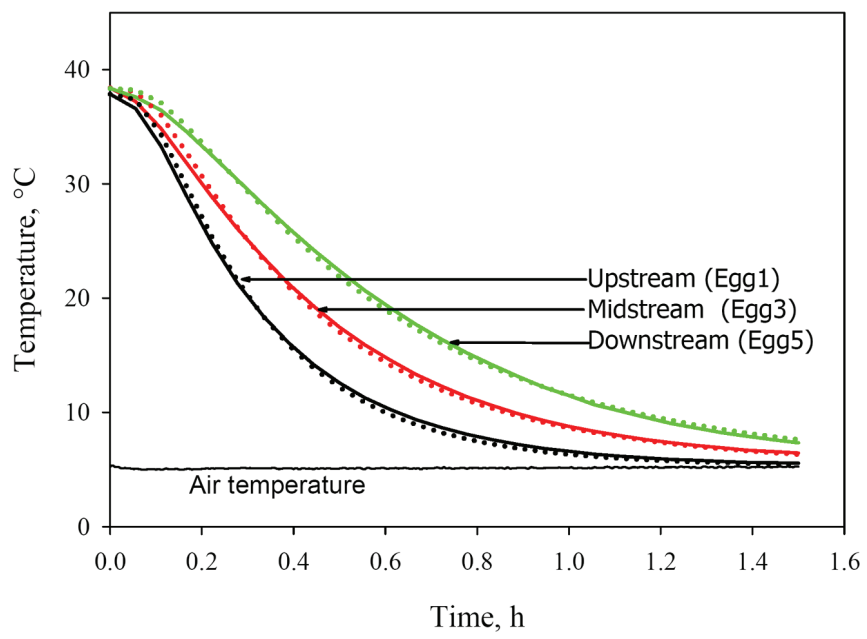

Fig. 11. Predicted (-) and observed (...) yolk temperature of eggs placed in middle layer in multiple trays subjected to pre-chilled cooling at 0.40 $\mathrm{m} / \mathrm{s}$ air velocity. 
an air velocity of $0.6 \mathrm{~m} / \mathrm{s}$ for an experimental duration of $1.5 \mathrm{~h}$ with a time step of $20 \mathrm{~s}$. The RMSE errors in egg yolk temperature prediction were $0.58{ }^{\circ} \mathrm{C}, 0.58{ }^{\circ} \mathrm{C}$, and $0.59^{\circ} \mathrm{C}$ for eggs placed at upstream, midstream, and downstream, respectively. In the beginning, the CFD model over predicted egg temperature and the maximum deviations were found to be $1.67^{\circ} \mathrm{C}, 1.56{ }^{\circ} \mathrm{C}$, and $1.36{ }^{\circ} \mathrm{C}$ at upstream, midstream, and downstream, respectively. The slightly larger error was due to a larger temperature difference between the incubated egg and the cooling air. At upstream end, the egg temperature was reduced from $39.18{ }^{\circ} \mathrm{C}$ to $6.32{ }^{\circ} \mathrm{C}$ in an hour at $0.6 \mathrm{~m} / \mathrm{s}$. The cooling curve is similar to concurrent cooling but the gradient of curve is steeper than concurrent cooling. The RMSE values for various simulations are summarized in Table 3.

\subsection{Simulation and experiment multiple Egg Trays}

Although, multiple trays are used in egg processing industries, we made a simplified assumption that the air velocity does not change considerably along the height of the stack, therefore similar temperature profiles are expected on all trays along the height of the stack. To validate this assumption, the experiments were conducted on multiple egg trays, and the simulations were carried out using the modified single egg tray CFD model. Fig. 11 compares experimental and predicted yolk temperature of upstream, midstream, and downstream eggs at $0.4 \mathrm{~m} / \mathrm{s}$ air velocity. The egg cooling is faster at upstream, moderate at midstream, and gradual at downstream end. The RMSE values of egg cooling at different air velocities are shown in Table 3.

The RMSE was of the same order as compared to single egg tray; this indicates that the assumption of five eggs in a row is sufficient to represent egg stacking and cooling arrangement. In most of the cases, the RMSE was less than $1^{\circ} \mathrm{C}$, which shows that the accuracy of CFD model is reasonable.

A slight deviation in predicted and experimental temperature would be attributed to the errors in experimentation, modeling assumptions, and numerical computation (Kumar et al., 2009). The experimental errors could be associated with temperature measurement by thermocouples whose accuracies were $\pm 0.5^{\circ} \mathrm{C}$ and velocity measurement contributed by hot wire anemometer whose accuracy was $5 \%$. The modeling assumptions viz., egg as composite material and constant thermal properties of egg and fluid would have contributed errors. Some errors in CFD prediction would be due to usage of Cartesian cut cell method. Unstructured grids may be used for this type of irregular geometry, but it would be computationally intensive. For practical purpose, the model accuracy is acceptable but it is good practice to check this with microbial growth model.

\subsection{Integration of microbial model with heat transfer model}

The results of the CFD model for the solution of the heat transfer model were sets of discrete time-temperature profiles. The egg yolk transient temperature profiles predicted by the CFD model and obtained experimentally under various heating or cooling scenarios were integrated into the dynamic SE growth model (Gumudavelli et al., 2007b) and the microbial growth results were obtained and compared. A pseudo initial value of $1 \log \mathrm{CFU} / \mathrm{g}$ of SE was assigned to the growth model and SE growth was calculated. The difference in the growth between the predicted and observed values was studied. Microbial growth corresponding to each scenario is presented in Table 4. From a food safety standpoint, the results showed that the difference in microbial growth predicted using simulated and

Table 4. Microbial growth prediction under different heat transfer conditions

\begin{tabular}{|c|c|c|c|c|c|}
\hline \multirow[t]{2}{*}{ Heat Transfer Mode } & \multirow[t]{2}{*}{ Velocity (m/s) } & \multirow[t]{2}{*}{ Egg Position } & \multicolumn{3}{|c|}{ Microbial growth, $\log _{10}(\mathrm{CFU} / \mathrm{g})$} \\
\hline & & & Observed & Predicted & Difference \\
\hline \multirow[t]{6}{*}{ Concurrent Cooling (Single Egg Tray) } & \multirow{4}{*}{0.3} & Upstream & 0.08 & 0.09 & 0.01 \\
\hline & & Midstream & 0.14 & 0.13 & 0.00 \\
\hline & & Downstream & 0.16 & 0.13 & -0.03 \\
\hline & & Upstream & 0.05 & 0.05 & 0.01 \\
\hline & \multirow[t]{2}{*}{0.6} & Midstream & 0.07 & 0.07 & 0.00 \\
\hline & & Downstream & 0.09 & 0.10 & 0.01 \\
\hline \multirow[t]{9}{*}{ Concurrent Heating (Single Egg Tray) } & \multirow{4}{*}{0.3} & Upstream & 1.98 & 2.11 & 0.13 \\
\hline & & Midstream & 1.96 & 2.01 & 0.05 \\
\hline & & Downstream & 1.90 & 1.95 & 0.05 \\
\hline & & Upstream & 2.38 & 2.52 & 0.14 \\
\hline & \multirow[t]{3}{*}{0.5} & Midstream & 2.46 & 2.47 & 0.01 \\
\hline & & Downstream & 2.36 & 2.39 & 0.03 \\
\hline & & Upstream & 5.33 & 5.53 & 0.21 \\
\hline & \multirow[t]{2}{*}{0.7} & Midstream & 5.55 & 5.50 & -0.05 \\
\hline & & Downstream & 5.54 & 5.49 & -0.05 \\
\hline \multirow[t]{12}{*}{ Pre-chilled Cooling (Single Egg Tray) } & & Upstream & 0.05 & 0.05 & 0.00 \\
\hline & \multirow{3}{*}{0.36} & Midstream & 0.07 & 0.07 & 0.00 \\
\hline & & Downstream & 0.08 & 0.09 & 0.00 \\
\hline & & Upstream & 0.06 & 0.06 & 0.00 \\
\hline & \multirow[t]{3}{*}{0.46} & Midstream & 0.08 & 0.07 & -0.01 \\
\hline & & Downstream & 0.10 & 0.09 & -0.01 \\
\hline & & Upstream & 0.04 & 0.05 & 0.00 \\
\hline & \multirow[t]{3}{*}{0.54} & Midstream & 0.05 & 0.05 & 0.00 \\
\hline & & Downstream & 0.06 & 0.06 & 0.00 \\
\hline & & Upstream & 0.04 & 0.04 & 0.00 \\
\hline & \multirow[t]{2}{*}{0.60} & Midstream & 0.05 & 0.05 & 0.00 \\
\hline & & Downstream & 0.05 & 0.06 & 0.00 \\
\hline \multirow[t]{6}{*}{ (Multiple Egg Trays) } & & Upstream & 0.05 & 0.05 & 0.00 \\
\hline & \multirow[t]{3}{*}{0.40} & Midstream & 0.08 & 0.08 & 0.00 \\
\hline & & Downstream & 0.11 & 0.11 & 0.00 \\
\hline & & Upstream & 0.04 & 0.04 & 0.00 \\
\hline & \multirow[t]{2}{*}{1.04} & Midstream & 0.05 & 0.05 & 0.00 \\
\hline & & Downstream & 0.07 & 0.06 & -0.01 \\
\hline
\end{tabular}




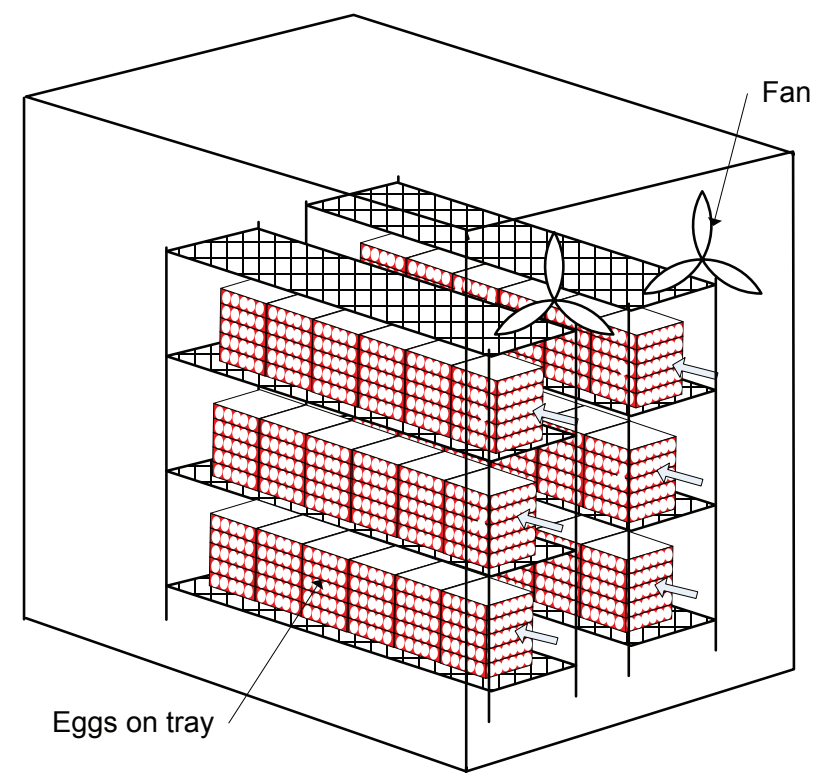

A. Schematic of pallet layout.

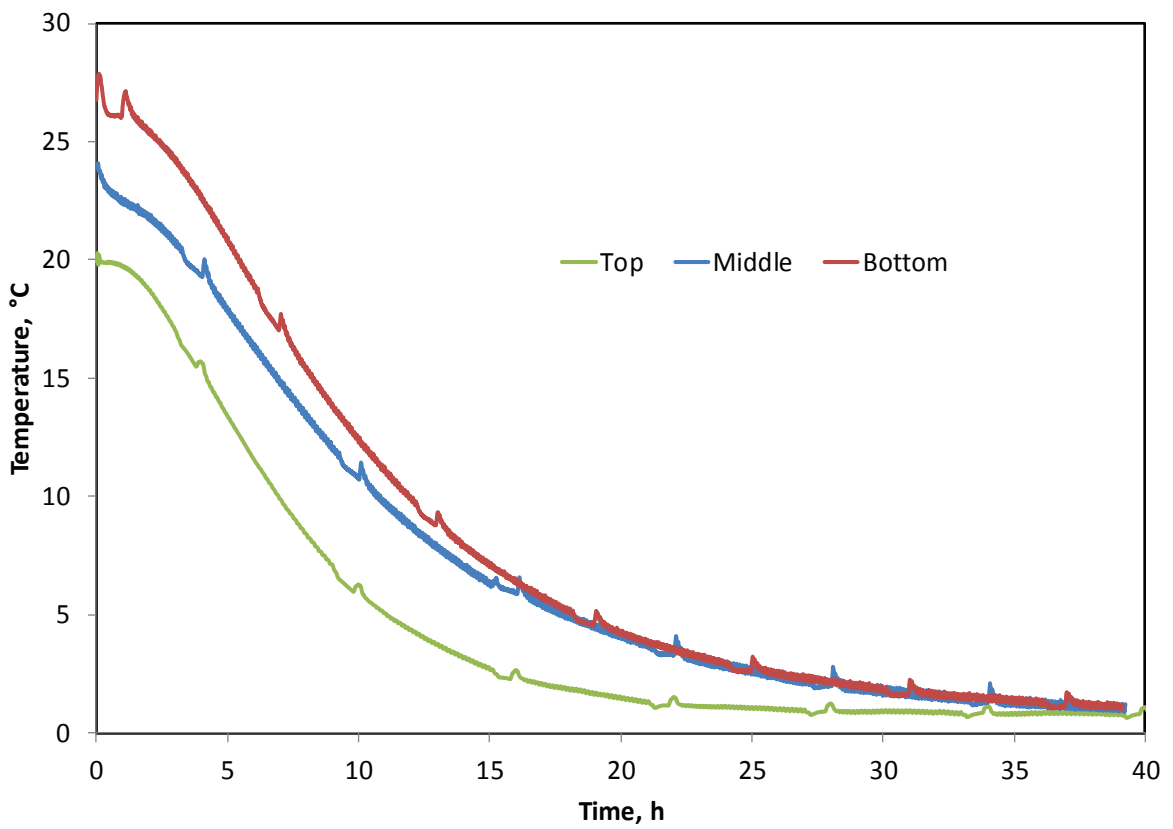

B. Temperature profiles of eggs placed on different racks.

Fig. 12. Cooling profile of eggs stacked on trays in a chilled room maintained around $2^{\circ} \mathrm{C}$.

experimental temperature profile was minimal (ranging from -0.05 $\log \mathrm{CFU} / \mathrm{g}$ to $0.21 \log \mathrm{CFU} / \mathrm{g}$ ). The microbial growth was lowest in pre-chilled egg cooling and highest in eggs subjected to concurrent heating. The microbial growth prediction using predicted temperature profile suggests that some discrepancy in temperature prediction would not significantly affect the microbial growth perdition. These prediction differences were so minimal that it is reasonable to conclude that the accuracy of the CFD model is reliable.

The integration of heat transfer model with the microbial model is vital for providing these tools to food safety managers in an egg processing plant. They do not fully understand the RMSE value in terms of temperature, because they cannot assess a certain RMSE value is good or not. However, if one can explain to them that this model predicts temperature profile such that when integrated with a microbial model, it estimates the SE growth within $0.21 \log (\mathrm{CFU}) / \mathrm{g}$, they can understand the accuracy of the model for their application and may start using this tool for daily operations.

In this study, the temperature close to the center of egg yolk was chosen for validation and estimation of SE growth, because it was easy to place the thermocouple close to the center of egg yolk for experiments. However the warmest location may not be at the center of yolk, because the cold air was blowing from one direction. For practical food safety risk assessment, the SE growth can be estimated in each and every finite volume grid within the yolk and can then be integrated to determine the total SE growth in the whole egg.

\subsection{Applications and limitations}

The heat transfer model has been developed and validated for various scenarios under controlled conditions in a wind tunnel. Com- 
prehensive validation of the CFD model using all possible scenarios has demonstrated the reliability of the modeling process. The developed model is the first step towards filling the data gap identified by FSIS risk assessment model. This work also demonstrated the integration of the heat transfer model with the microbial growth model to assess the potential growth of SE during cooling. One potential application of the model is to evaluate the effect of pre-chilling the trays and the effect of thermal conductivity of tray materials (by changing the tray material) on cooling rate of the eggs. Out of various scenarios validated in this study, the "pre-chilled cooling" is the one most commonly encountered in the egg industry. In this scenario, the warm eggs are placed in the pre-chilled room. Fig. 9 shows that the eggs can be cooled in less than an hour for this scenario and the potential growth of SE is less than $0.1 \log \mathrm{CFU} / \mathrm{mL}$ (Table 4). If this were realistic, there should not be any food safety issues related to egg chilling. However, there have been several outbreaks of SE in shell eggs. This indicates that the developed model is not yet representing actual scenarios encountered in industrial forced air cooling.

\subsection{Egg cooling dynamics in chiller room}

To understand the cooling of eggs in a chiller room, we conducted a preliminary study. Five trays each containing 30 eggs stacked one over the other. Six such stacks were placed adjacent to each other without any gaps as shown in Fig 12. Each egg stack was wrapped on the sides, top and bottom, with multiple layers of multipurpose sealing wrap (Glad Press n' Seal, Oakland, California, USA). This prevented air escaping from the sides and forced air to enter only from the front of the egg stacks. This mimics the industrial condition wherein eggs in the middle of the cooler room are not exposed to any air circulation from the sides, top and bottom. In the cooler room (10 $\times 12$ feet) two fans, mounted on one side of the wall closer to ceiling, circulated air over a cooling coil to maintain the chiller room around $2^{\circ} \mathrm{C} \pm 1^{\circ} \mathrm{C}$. Egg core temperature was monitored at multiple locations in different stacks as shown in Fig. 12a. Approximately 25-30 hours of cooling was required to chill the eggs in the bottom, whereas 1520 hours was required to chill the eggs on the top racks (Fig. 12b). Significant difference in cooling rate was attributed by differential air blowing on the top and bottom of the rack from the overhead fans. In contrast, the eggs were cooled in less than 2 hours (Fig. 10 and Fig. 11) in the validation study.

This study highlights that egg cooling in industrial settings is quite different from cooling profiles validated in the wind tunnel. The major reason for fast cooling in wind tunnel was due to the fact that the air was forced through the egg pallet. In industrial settings, however, there seems to be negligible air movement through the pallet. Any air movement is mainly due to the natural convection rather than forced convection in the stack of pallets.

\subsection{Suggestions for future work}

The current CFD model considers forced air convection, whereas natural convection seems to be predominant in industrial conditions. The current CFD model was developed with a finer scale (mesh size) to evaluate the temperature distribution within the eggs. Finer mesh sizes are required to approximate the curved surface of eggs and narrow air gaps between egg and tray. Due to computational complexity, this model cannot be extended to cover all stacks within a chilling room to consider natural convection of air diffusing through the porous pallet. Therefore, another CFD model at a larger scale is needed to include the whole chilling room in the computational domain, with each stack as a block with appropriate porosity value for the air to diffuse through the stack. Such model development approach will be able to evaluate the effect of the layout of stacks (frequency and amount of stack spacing) on cooling rate and uniformity among the eggs in various stacks within the chilling room.

\section{Conclusions}

In order to evaluate the effect of cooling on microbial safety of shell eggs, an integrated model consisting of heat transfer and microbial model was developed. The CFD model was validated from a thermal point of view under various cooling and heating conditions. There was a good agreement between predicted and measured egg yolk temperature at different locations, viz., upstream, midstream, and downstream as RMSE was less than $1{ }^{\circ} \mathrm{C}$ in most of the cases. In the case of concurrent cooling, the RMSE was $0.35^{\circ} \mathrm{C}$ and in the case of concurrent heating the RMSE was in the range of 0.25 $-0.50{ }^{\circ} \mathrm{C}$. The CFD model developed for single pallet was further validated with experimental results obtained from multiple pallets. The predicted egg temperatures profile and the observed temperature profiles were fed into a microbial SE growth model to predict its population at the end of chilling period. The integrated model predicted final microbial population with mean error of $0.015 \mathrm{log}$ $\mathrm{CFU} / \mathrm{g}$ and a maximum error of $0.21 \log \mathrm{CFU} / \mathrm{g}$. Successful validation of the CFD model using all possible scenarios has demonstrated the reliability of the model. The developed model is the first step towards filling the knowledge gap identified by FSIS risk assessment model. Another CFD model incorporating the whole chiller room as a domain is required to evaluate the safety of eggs chilled under industrial settings.

\section{Notation}

$$
\begin{aligned}
& \frac{\partial}{\partial x_{i}}=\frac{\partial}{\partial x}, \frac{\partial}{\partial y}, \frac{\partial}{\partial z} \\
& \frac{\partial}{\partial x_{j}}=\frac{\partial}{\partial x}+\frac{\partial}{\partial y}+\frac{\partial}{\partial z} \\
& U_{j} \cdot \frac{\partial}{\partial x_{j}}=U_{x} \cdot \frac{\partial}{\partial x}+U_{y} \cdot \frac{\partial}{\partial y}+U_{z} \cdot \frac{\partial}{\partial z}
\end{aligned}
$$

\section{Terminology}

Upstream: $\quad$ Egg location at the beginning of a row of an egg tray

Midstream: and facing incoming fluid

Egg location at the middle row of an egg tray

Downstream: Egg location at the end of a row of an egg tray facing and exposed to outgoing fluid

Acknowledgement - The authors acknowledge the financial support from USDA, National Integrated Food Safety Initiative under agreement 200651110-03664. Authors are also thankful to Robert Weber and Scott Minchow in setting up experiments in the wind tunnel.

\section{References}

Almonacid, S., Simpson, R., \& Teixeira, A. (2007). Heat transfer models for predicting Salmonella Enteritidis in shell eggs through supply chain distribution, Journal of Food Science, , 72(9), 508-517.

Baranyi, J., Roberts, T. A. 1994. A dynamic approach to predicting bacterial growth in food. International Journal of Food Microbiology, 23, 277-294. 
CDC (2006). Surveillance for foodborne-disease outbreaks - United States, 1998-2002, http://www.cdc.gov/mmwr/preview/mmwrhtml/ss5510a1. htm, accessed October 2008.

CDC (2007) Three Outbreaks of salmonellosis Associated with Baby Poultry from Three Hatcheries - United States, 2006, http://www.cdc.gov/ $\mathrm{mmwr} / \mathrm{preview} / \mathrm{mmwrhtml} / \mathrm{mm} 5612 \mathrm{al} . \mathrm{htm}$, accessed October 2008.

CDC (2010). Wright County Egg Conducts Nationwide Voluntary Recalls of Shell Eggs Because of Possible Health Risk, United States, http://www.fda.gov/Safety/Recalls/ucm222501.htm, accessed Sept 22, 2010.

CFD Wiki (2010), Turbulence length scale, Estimating the turbulence length scale, http://www.cfd-online.com/Wiki/Turbulence_length_scale.

CFD Wiki (2010), Best practice guidelines for turbomachinery CFD, Turbulence inlet conditions, http://www.cfd-online.com/Wiki/ Best_practice_guidelines_for_turbomachinery_CFD

Cengel, Y.A.(2007), Properties of air $1 \mathrm{~atm}$ pressure , Heat and Mass Transfer, Tata McGraw Hill., New Delhi, 860.

Choi, Y. \& Okos, M.R. (1986). Effect of temperature and composition on the thermal properties of foods. In Food Engineering and Process Applications, Vol.1, - Transport Phenomena, Le Maguer, M. \& Jelen, P., Eds., Elsevier, New York, 93-101.

ESI (2010), Guidelines for Specification of Turbulence at Inflow Boundaries, About Turbulence Intensity, http://support.esi-cfd.com/esi-users/ turb_parameters/

Feddes, J.J.R., Robinson, F.E., Korver, W., Koberstein, B., \& Watson, L.D. (1993). Internal cooling rates of stored eggs: effects of packing and egg size, The Journal of Applied Poultry Research, 324-329.

FSIS (2005). Risk Assessments of Salmonella Enteritidis in Shell Eggs and Salmonella spp. in Egg Products, http://www.fsis.usda.gov/PDF/SE_ Risk_Assess_ExecSumm_Oct2005.pdf, accessed August 2007.

Gumudavelli, V. (2006). An integrated model for heat transfer and dynamic growth of Salmonella Enteritidis in shell eggs, M.S. Thesis, University of Nebraska, Lincoln, USA.
Gumudavelli V., Subbiah J., Thippareddi, H., Wang L., \& Weller, C. (2007a). Finite element modeling of heat transfer in shell eggs, American Society of Agricultural and Biological Engineers Annual International Meeting, Minneapolis, USA.

Gumudavelli, V., Thippareddi, H., Velugoti, P., Froning, G. (2007b). Dynamic predictive model for growth of Salmonella Enteritidis in egg yolk, Journal of Food Science, 72 (7), 254-262.

Kumar, V, Jonnalagadda, D., Wee, A.P., Subbiah, J., Thippareddi, H., Birla, S. (2009). A 3-D heat transfer and fluid flow model for cooling of a single egg under forced convection, ASABE, 52(5),1627-1637.

Launder, B.E., and Spalding, D.B. (1974). The numerical computation of turbulent flows, Computational Method, Applied Mech. Eng., $3,269-289$.

Li, X., J. Meng, and Guo, Z. (2009). Turbulent flow and heat transfer in discrete double inclined ribs tube. Int. J. Heat Mass Transfer (Press), 52, 962-970.

Pham, Q. T. 2001. Modelling thermal processes: cooling and freezing. In Food process modeling. Ed. by Tijskens, L.M.M., Hertog, M. L. A. T. M., and Nicolaï, B. M. Woodhead Publishing Ltd., Boca Raton, FL.

PHOENICS, PHOENICS user guide, CHAM London. UK, (2008).

PHOENICS (2008) Two-Scale k- $\varepsilon$ Turbulence Model, Inlet Boundary Conditions http://www.cham.co.uk/phoenics/d_polis/d_enc/turmod/ enc_t $414 . \mathrm{htm}$

Sabliov, C.M., Farkas, B.E., Keener, K.M., \& Curtis, P.A. (2002).Cooling of shell eggs with cryogenic carbon dioxide: a finite element analysis of heat transfer, Lebensmittel-Wissenschaft und-Technologie, 35(7), 568-574.

Spalding, D.B. (1980). Mathematical modeling of fluid mechanics, heat transfer and mass transfer processes, Mechanical Engineering Department, Report HTS/80/1. Imperial College of Science, Technology and Medicine, London.

Zwietering, M.H., De Koos, J.T., Hasenack, B. E., DeWit, J. C., Van't Riet, K. 1991. Modeling of the bacterial growth as a function of temperature. Applied and Environmental Microbiology, 57(4),1094-101. 